\title{
CANADIAN OXYGEN PRIZE
}

(Formerly British Oxygen (Canada) Prize)

Canadian Oxygen Limited have made available the sum of $\$ 1,000$ annually for the prize to be awarded by the Canadian Anaesthetists' Society for the best original work in Anaesthesia completed in Canada during the year preceding the award. The second such prize will be awarded at the time of the Annual Meeting of the Canadian Anaesthetists' Sooiety in 1963. The following regulations apply:

\section{Qualifications}

1. Applicant must be a resident in training in Anaesthesia or a practising anaesthetist.

2. The study must be carried out in a Canadian Hospital or University, and must have been completed during the previous 12 months.

3 . The study submitted may be of a basic or a $c$ inical nature.

\section{Submission and Selection}

1. Applicant's study is to be submitted in quadruplicate to the Secretary, Canadian Anaesthetists' Society, prior to December 31st, 1962. The paper should not contain the name of the author, which will be communicated to the Secretary in a covering letter only.

2. Where more than one person has participated in the work reported, the application for the prize must be made in the name of one of them only.

3. Each applicant for the Canadian Oxygen Prize must be prepared to present such report in the programme of the Annual Meeting of the Canadian Anaesthetists' Society. The right of publication of all reports submitted in application for the prize is reserved to the Canadian Anaesthetists' Society Journal subject to acceptance by the Editor.

4. Four (4) referees will be appointed by the Executive of the Canadian Anaesthetists' Society from departments of Anaesthesia in Canadian Universities. Not more than one referee shall be chosen from any one University.

5. In the event of two (2) applicants submitting work judged by the referees to be of equal merit, the award may be divided at the discretion of the referees.

6 . If in the opinion of the referees the studies submitted do not warrant the award being made in any year, the prize will be doferred. 